\title{
Peningkatan Produktivitas Industri Manisan Nanas Melalui Pengembangan Pengering Multi Rak
}

\author{
Mohamad Endy Yulianto ${ }^{1}$, Eflita Yohana ${ }^{2}$, Sutrisno $^{3}$, Sri Utami $\mathrm{H}^{3}$, Didik Ariwibowo ${ }^{3}$, \\ Fardzanela S. ${ }^{4}$ dan Riana Sitawati ${ }^{5}$ \\ ${ }^{1}$ Program Studi Teknik Kimia, Departemen Teknologi Industri, Sekolah Vokasi, Universitas Diponegoro \\ Jl. Prof. Soedarto, Tembalang, Semarang, Jawa Tengah 50275, Indonesia \\ 2Jurusan Teknik Mesin, Fakultas Teknik Universitas Diponegoro \\ Jl. Prof. Soedarto, Tembalang, Semarang, Jawa Tengah 50275, Indonesia \\ ${ }^{3} J u r u s a n$ Teknik Mesin, Sekolah Vokasi, Universitas Diponegoro \\ Jl. Prof. Soedarto, Tembalang, Semarang, Jawa Tengah 50275, Indonesia \\ ${ }^{4} J u r u s a n$ Teknik Sipil Sekolah Vokasi, Universitas Diponegoro \\ Jl. Prof. Soedarto, Tembalang, Semarang, Jawa Tengah 50275, Indonesia \\ ${ }^{5} J u r u s a n$ Akuntansi Fakultas Ekonomi STIE Dharmaputra \\ Jl. Pamularsih Raya No.16, Semarang, Jawa Tengah 50141, Indonesia \\ Email:endy_y@yahoo.com
}

\begin{abstract}
Abstrak
Industri olahan buah-buahan khususnya nanas menjadi salah satu industri yang cukup berkembang. Olahan hasil panen nanas dilakukan untuk meningkatkan nilai tambah produk ini.Tujuan kegiatan ini adalah deseminasi teknologi pengering multi rak resirkulasi adsorpsi berbasis zeolit yang telah teruji di laboratorium dan merupakan well-proven technology ke industri manisan nanas rumput laut KUB 3 Sekawan. Target yang ingin dicapai melalui pengembangan proses produksi dan konsep pengering resirkulasi berbasis zeolit di industri manisan nanas rumput laut KUB 3 Sekawan mampu meningkatkan produktivitas dan efisiensi produksi. Kegiatan diseminasi produk teknologi ke masyarakat meliputi: (i) desain dan pabrikasi prototipe pengering resirkulasi adsorpsi kapasitas $50 \mathrm{~kg} / \mathrm{batch}$, (ii) penyusunan dokumen Standard Operating Procedures (SOP), (iii) pengujian adaptasi dan evaluasi penerapan pengering resirkulasi adsorpsi, dan (iv) evaluasi teknoekonomi. Pengering multi rak dilengkapi resirkulator udara pengering berbasis zeolit telah terpabrikasi secara baik dan telah digunakan untuk produksi manisan nanas rumput laut. Pengering adsorpsi multi rak ini, mampu meningkatkan kapasitas produksi dan menurunkan biaya produksi. Analisis tekno-ekonomi meliputi: B/C Ratio, NPV dan IRR menunjukkan bahwa terap-kembang alat di industri manisan nanas rumput laut ini layak. Dengan demikian, alat memenuhi persyaratan secara teknis dan secara finansial atau secara ekonomis.
\end{abstract}

Kata kunci: adsorpsi; manisan nanas; pengering; resirkulasi; zeolite

\section{PENDAHULUAN}

Kabupaten Pemalang merupakan salah satu kabupaten di Provinsi Jawa Tengah yang terletak di pantai utara Pulau Jawa. Secara astronomis Kabupaten Pemalang terletak antara $109^{\circ} 17^{\prime} 30^{\prime \prime}$ - 109 40' 30" BT dan $8^{\circ} 52^{\prime} 30^{\prime \prime}-7^{0} 20^{\prime} 11^{\prime \prime}$ LS. Kabupaten Pemalang memiliki luas wilayah sebesar $1.115,30 \mathrm{~km}^{2}$. Sebelah Utara berbatasan dengan Laut Jawa, di sebelah Selatan berbatasan Purbalingga, sebelah Timur berbatasan Pekalongan dan di sebelah Barat berbatasan dengan Kabupaten Tegal. Dengan demikian Kabupaten Pemalang memiliki posisi yang strategis, baik dari sisi perdagangan maupun pemerintahan.

Tulang punggung perekonomian di Kabupaten Pemalang adalah sektor pertanian 
dengan lahan sawah seluas 38.617 hektar dan lahan kering 23.813 hektar, komoditas yang menonjol untuk tanaman pangan adalah padi, ketela pohon dan jagung, sayur-sayuran, bawang merah, cabai merah dan ketimun. Sedangkan produksi buah-buahan adalah nanas batu, pisang dan manga.

Nanas batu merupakan salah satu komoditas unggulan yang memiliki potensi sangat baik. Nanas batu sering juga dinamakan nanas madu karena memiliki rasa yang sangat manis, jauh lebih manis dibandingkan dengan nanas pada umumnya. Disebut nanas batu karena nanas ini tumbuh di dataran tinggi daerah Pemalang yang lapisan tanahnya tipis dan berbatu-batu. Tanaman ini tumbuh subur di daerah Kecamatan Belik, lebih tepatnya di Desa Beluk dan Desa Bulakan. Areal yang ditanami nanas batu mencapai luas 800 hektar. Keunikan tanaman ini adalah bahwa rasa nanas yang dihasilkan akan berubah menjadi masam, lembek dan lebih berair ketika bibitnya ditanam diluar daerah Kecamatan Belik.

Tanaman nanas madu berbuah sepanjang tahun, dapat dikatakan tanaman ini tidak mengenal musim, sehingga potensinya sangat besar. Selama ini nanas madu banyak dijual dalam bentuk buah segar yang dikirimkan ke daerah sekitar Pemalang dan luar daerah seperti Pekalongan, Semarang, Tegal, Yogyakarta hingga Jakarta. Harga per buah bervariasi tergantung besar kecilnya, berkisar antara Rp. 2.500 sampai dengan Rp. 4000 perbuah dari petani. Penjualan dalam bentuk buah segar memiliki kelemahan yaitu daya simpan buah nanas yang singkat. Bila buah nanas dipanen pada kondisi matang, maka rasa manisnya akan maksimal namun mudah busuk. Buah yang telah matang sempurna dapat bertahan 2 sampai 3 hari setelah dipetik, sehingga rentan busuk ketika harus dikirim ke luar daerah terutama pada kondisi cuaca yang panas dan tertutup rapat. Bila nanas dipetik pada kondisi kurang matang, daya simpannya cukup lama berkisar 5 hari, namun rasanya kurang manis.

Industri pengolahan nanas madu belum berkembang di daerah Pemalang, meskipun potensi bahan baku sangat besar. Industri kecil menengah yang mngolah nanas madu berlokasi di Desa Beluk, Kecamatan Belik. Produk yang dihasilkan bervariasi antara lain manisan nanas, dodol nanas, stik nanas, krupuk nanas dan manisan nanas rumput laut. Manisan nanas rumput laut merupakan produk yang paling disukai konsumen karena rasanya yang unik dan manfaatnya sebagai snack sehat mengandung serat.

Bahan baku pengolahan manisan nanas rumput laut adalah nanas madu, rumput laut kering, gula pasir, dan agar agar bubuk. Proses produksi tersaji pada Gaambar 2 meliputi: rumput laut direndam dalam air selama 1 malam lalu ditiriskan, dikukus dan diblender. Nanas dikupas, dicuci dan diblender. Kedua bahan tersebut dicampur dengan agar-agar bubuk dan gula, direbus sambil diaduk-aduk. Setelah mendidih, dituang pada loyang plastik dan dibiarkan mengeras. Ketika adonan mengeras, dipotongpotong sesuai dengan ukuran yang diinginkan. Irisan manisan kemudian dikeringkan dengan cara dihamparkan pada tampah untuk dijemur dibawah sinar matahari, setelah setengah kering ditaburi gula pasir dan dijemur kembali hingga kering, manisan siap dikemas. Total waktu yang dibutuhkan untuk proses pengeringan mencapai 3 hari. Ketika musim hujan proses pengeringan tidak menggunakan sinar matahari, namun menggunakan oven. Pengeringan dengan oven dilakukan pada suhu yang hampir sama dengan suhu pemanasan dengan sinar matahari yaitu berkisar $40-50^{\circ} \mathrm{C}$, selama 7 hari.

Daerah pemasaran produk manisan nanas rumput laut sudah meliputi Jawa Tengah dan sekitarnya khususnya Kabupaten Pemalang. Manisan nanas rumput laut ini dijual dengan harga Rp 18.500,- tiap kemasan 200 gr. Namun demikian, produk manisan nanas rumput laut yang dihasilkan saat ini tidak mampu memenuhi permintaan pasar. Hal ini disebabkan oleh kapasitas produksi relatif rendah yang hanya mampu membuat 10 kali produksi/bulan dengan kapasitas $150 \mathrm{~kg} / \mathrm{bulan}$. Rendahnya kapasitas produksi ini dikarenakan proses penjemuran manisan yang memakan waktu kurang lebih 3 hari, terlebih jika musim penghujan mencapai 7 hari. Oleh karenanya setiap batch produksi paling cepat dibutuhkan waktu sekitar 3 hari.

Sebagai usaha untuk memenuhi tuntutan pasar yang mengharapkan produk-produk olahan terjaga tingkat hygienitas, baik kemasan maupun produk yang dihasilkan. 
Persoaalan pada proses produksi saat ini adalah terletak pada lamanya waktu pengeringan yang menyebabkan peningkatan produktivitas usaha manisan nanas rumput laut sulit tercapai. Meskipun bantuan alat produksi dari PNPM Mandiri berupa oven yang digunakan untuk pengeringan manisan nanas rumput laut telah digunakan disaat musim penghujan. Namun demikian, belum mampu meningkatkan produktivitas. Hal ini disebabkan pengering manisan dengan menggunakan oven hanya dikondisikan pada suhu $40-50{ }^{\circ} \mathrm{C}$, akibatnya dibutuhkan waktu hingga 7 hari. Apabila suhu ditingkatkan supaya mempercepat waktu pengeringan, akan tetapi produk manisan yang dihasilkan warnanya berubah kecoklatan. Adapun penyebab utamanya adalah kandungan gula yang relatif besar sebanding dengan jumlah nanas dan rumput laut dimungkinkan menyebabkan terjadinya karamelisasi dan reaksi maillard pada pengeringan diatas suhu $80{ }^{\circ} \mathrm{C}$. Untuk itu pengembangan pengering adsorpsi multi rak, merupakan terobosan yang sangat menarik, karena mampu meningkatkan efisiensi dari segi tekno-ekonomi. Hasil riset dan penerapan teknologi pengering berbasis olahan dengan skala laboratorium dan pilot plant telah dilakukan, menunjukkan bahwa dengan teknologi dan peralatan yang telah dirancang dan dipabrikasi, proses operasi pengering dapat dilaksanakan dengan hasil yang memuaskan (Ariwibowo et al., 2014; Handayani et al., 2015).

Aplikasi teknologi pengering adsorpsi multi rak mampu mereduksi bahkan meniadakan terjadinya reaksi maillard pada manisan disamping menghindari case hardening (Mujumdar, 2002; Ariwibowo, et al., 2012). Pengering superheated steam (resirkulasi) ini juga mampu meningkatkan efisiensi energi mencapai $400 \%$ jika dibandingkan pengering dengan udara panas (Stubbing, 1999; Mujumdar, 2002). Bahkan metode pengeringan dengan superheated steam akan meningkatkan produktivitas hingga 35\% dibanding pengering dengan udara panas (Mujumdar, 2002; Ariwibowo et al., 2013). Hal ini disebabkan oleh peningkatan temperatur manisan. Fenomena yang terjadi pada pengering konveksi udara panas, temperatur permukaan sama dengan temperatur bola basah terkait dengan kelembaban relatif dan temperatur bola kering. Sedangkan pada pengering superheated steam, temperatur permukaan sama dengan temperatur steam, yaitu $100{ }^{\circ} \mathrm{C}$. Temperatur yang lebih tinggi akan berdampak pada peningkatan temperatur manisan, sehingga akan meningkatkan difusivitas air dalam padatan (Mujumdar, 2002; Nwabane, 2009). Oleh karenanya, perlu pengembangan aplikasi pengering resirkulasi adsorpsi multi rak di sentra industri manisan nanas rumput laut untuk meningkatkan produktivitas, efisiensi energi, efisiensi kerja, peningkatan hasil dan perbaikan mutu manisan.

\section{METODOLOGI}

Riset skala laboratorium dan pilot plant maupun simulasi proses menghasilkan data-data tentang karakteristik pengering olahan pangan, data pengoperasian alat pengering, dan data-data teknis desain dan scale-up pengering resirkulasi. Teknologi pengering ini sudah teruji di laboratorium dan merupakan well-proven technology (Ariwibowo et al., 2012; 2013; 2014; Handayani et al., 2015; Yohana et al., 2016). Datadata ini menjadi acuan untuk melakukan desain, uji adptasi dan aplikasi penerapan pengering resirkulasi. Uji adaptasi dan aplikasi penerapan pengering merupakan tahapan penting dalam aplikasi teknologi pengering resirkulasi untuk mengeringkan manisan nanas rumput laut.

Kegiatan diseminasi ini meliputi: (i) desain dan pabrikasi prototipe pengering resirkulasi adsorpsi kapasitas $50 \mathrm{~kg} /$ batch, (ii) penyusunan dokumen Standard Operating Procedures (SOP), (iii) pengujian adaptasi dan evaluasi penerapan pengering resirkulasi adsorpsi, dan (iv) evaluasi tekno-ekonomi.

\section{Uji Adaptasi dan Evaluasi Penerapan}

Kegiatan uji adaptasi dan evaluasi penerapan dimonitor oleh Pemda Pemalang (Kantor Ketahanan Pangan, Dinas Koperasi UKM Perindustrian dan Perdagangan) dan dikoordinasi oleh LPPM UNDIP. Parameter yang diamati pada saat kegiatan meliputi parameter sifat-sifat fisik dan kimia manisan nanas rumput laut, kondisi lingkungan, performa mesin dan ekonomi. Parameter sifat fisik dan kimia antara lain meliputi: (i) persyaratan pengeringan manisan, (ii) kadar air awal bahan, (iii) kadar air akhir bahan, (iv) densitas 
bahan, (v) temperatur pengeringan, (vi) temperatur lingkungan, dan (vii) kelembaban relatif. Parameter performa mesin meliputi: (i) waktu pengeringan, (ii) konsumsi bahan bakar, (iii) laju pengeringan, (iv) efisiensi penggunaan energi, dan (v) kapasitas ruang pengering. Parameter sosial ekonomi meliputi: ongkos kerja, harga alat, umur ekonomi, biaya pokok, biaya operasional, $\mathrm{b} / \mathrm{c}$ ratio dan lain-lain.

\section{HASIL DAN PEMBAHASAN}

\section{Desain dan Pabrikasi Pengering Multi Rak dengan Dehumidifikasi Adsorpsi}

Desain pengering multi rak dengan dehumidifikasi adsorpsi berbasis zeolit kapasitas $50 \mathrm{~kg} / \mathrm{batch}$. Desain pengering berdasarkan hasil riset Tim Pelaksana meliputi perhitungan dimensi utama masing masing komponen diikuti dengan penggambaran detail alat dengan software autocad dan solidwork (Ariwibowo et al., 2014; Handayani et al., 2015; Yohana et al., 2015) yang dikompilasi dari rujukan desain pengering Mujumdar (2002). Untuk menggambarkan kinerja peralatan yang telah dibuat, dilakukan simulasi CFD terlebih dahulu dengan software Fluent. CFD merupakan metode penghitungan, memprediksi dan pendekatan aliran fluida secara numerik dengan bantuan komputer. Penggunaan CFD dapat diprediksi karakteristik aliran fluida, datadata perpindahan panas dan massa, proses kimia serta parameter-parameter yang berpengaruh yang terjadi pada masing-masing komponen peralatan. Desain masing-masing komponen dapat dilakukan dengan lebih tepat dan efisien karena dapat diubah-ubah sehingga diperoleh kondisi yang diinginkan (Ahuja \& Patwardhan, 2008).

\section{Produksi Manisan Nanas Rumput Laut dengan Pengering Multi Rak}

Produksi manisan nanas rumput laut dengan menggunakan pengering multi rak berbasis zeolite telah dilakukan pada suhu $60{ }^{\circ} \mathrm{C}$ dengan kapasitas $50 \mathrm{~kg}$ manisan basah tiap batch. Akan tetapi untuk produksi ini belum menggunakan zeolite untuk mereduksi kelembaban udara panas. Namun demikian, hasil pengering multi rak ini sangat luar biasa sekali, karena mampu mengeringkan hanya dalam waktu
24 jam (selama 3 hari). Hal ini disebabkan oleh distribusi udara pengering dapat merata disamping laju alir udara pengering memiliki kecepatan yang relativ cepat.

Waktu yang dibutuhkan untuk mengeringkan manisan nanas rumput laut sekitar 4 jam. Bila dibandingkan dengan kondisi oven yang lama, proses pengeringan ini membutuhkan waktu sekitar 3 hari, maka terjadi pengurangan waktu pengeringan yang sangat besar. Hal ini tentu saja akan meningkatkan kapasitas produksi dan menurunkan biaya produksi.

\section{Analisis Tekno-Ekonomi dengan Pengering Multi Rak Berbasis Zeolit}

Analisis tekno-ekonomi alat dilakukan untuk menentukan keefektifan alat yang digunakan sebagai alat produksi manisan nanas berbahan baku utama buah nanas, dan untuk menentukan kelayakan finansial. Keefektifan alat atau aspek teknis alat menunjukkan bahwa alat dapat digunakan secara efektif atau mampu berproduksi menghasilkan manisan nanas. Alat dapat digunakan secara berulang dengan hasil produksi yang relatif seragam, dengan kapasitas terpasang $50 \mathrm{~kg} /$ batch.

Aspek keuangan merupakan cara atau rujukan untuk menentukan rencana investasi melalui perhitungan biaya dan manfaat yang diharapkan, dengan membandingkan antara pengeluaran dan pendapatan. Dalam melakukan investasi diperlukan perhitungan kemungkinan keuntungan yang tinggi agar harapan untuk mendapatkan nilai lebih pada waktu mendatang dapat tercapai. Sebagai tolak ukur analisis finansial diperlukan parameter-parameter yang berasal dari analisa sebelumnya, antara kapasitas produksi, pangsa pasar, teknologi yang dipakai, pilihan peralatan, jumlah tenaga kerja, fasilitas pendukung dan proyeksi harga-harga (Hidayat, 2013).

Perkiraan biaya diperlukan asumsi-asumsi yang menjadi dasar perhitungan biaya. Asumsiasumsi tersebut antara lain adalah (i) umur ekonomis proyek direncanakan selama 10 tahun, Umur proyek ini ditentukan berdasarkan lama waktu pabrikasi, setting, instalasi dan uji coba mesin, (ii) nilai sisa mesin 0 persen dari nilai awal pada tahun ke-10, (iii) kapasitas produksi yang akan diraih dan perhitungan neraca massa adalah 
sebagai berikut: (1) kebutuhan bahan baku: buah nanas segar $500 \mathrm{~kg} /$ hari, (2) kapasitas produksi manisan nanas dan bola-bola nanas adalah 15 $\mathrm{kg} /$ hari dan $10 \mathrm{~kg} /$ hari, (3) lama operasi: 6 jam/hari, dengan jumlah hari kerja 300 hari/tahun, (4) harga-harga yang digunakan dalam analisa finansial ini berdasarkan harga pada saat analisis kelayakan tahun 2017 dan selama tahun perencanaan yang dipengaruhi discount factor sebesar $12 \%$ di bank, (5) harga bahan baku dan produk diasumsikan mengalami kenaikan $5 \%$ per tahun, (6) pajak diasumsikan tetap selama periode 10 tahun sebesar $10 \%$ per tahun sebagai Pajak Pertambahan Nilai (PPN).

Hasil analisis kelayakan finansial menunjukkan bahwa Break Even Point (BEP) alat terjadi pada bulan ke-22. Nilai Benefit-Cost Ratio (B/C Ratio) sebesar 1,74 menunjukkan bahwa dengan peralatan yang diterap-kembangkan memberikan manfaat yang lebih besar dari biaya yang ditimbulkan (syarat nilai B/C Ratio>1). Net Present Value, yang merupakan selisih dari pendapatan dan pengeluaran yang dinilai pada awal proyek. Nilai NPV hasil analisis tersebut adalah positif Rp. 288.387.163. Ini berarti bahwa proyek akan mengarah pada keuntungan dan bukan pada kerugian. Internet Rate of Return (IRR) merupakan indikator kelayakan investasi yang nilainya dibandingkan dengan discount factor Bank. Discount factor Bank diasumsikan 12\%. Nilai IRR terkalkulasi sebesar $81,43 \%$. Nilai ini jauh lebih besar dari discount factor Bank sehingga dapat digunakan untuk memutuskan bahwa menginvestasikan dana pada terap-kembang alat di industri manisan nanas akan lebih menguntungkan daripada investasi dengan cara menyimpan dana di Bank. Secara keseluruhan, analisis B/C Ratio, NPV dan IRR menunjukkan bahwa terap-kembang alat di industri manisan nanas ini layak. Dengan demikian, alat memenuhi persyaratan secara teknis dan secara finansial atau secara ekonomis.

\section{KESIMPULAN}

Pengering multi rak dilengkapi resirkulator udara pengering berbasis zeolit telah terpabrikasi secara baik dan telah digunakan untuk produksi manisan nanas rumput laut. Pengering adsorpsi multi rak ini, mampu meningkatkan kapasitas produksi dan menurunkan biaya produksi. Analisis tekno-ekonomi meliputi: B/C Ratio, NPV dan IRR menunjukkan bahwa terap-kembang alat di industri manisan nanas rumput laut ini layak. Dengan demikian, alat memenuhi persyaratan secara teknis dan secara finansial atau secara ekonomis.

\section{UCAPAN TERIMA KASIH}

Pada kesempatan ini, penulis mengucapkan syukur Alhamdulillah kepada Allah SWT dan terima kasih yang sebesar-besarnya kepada RISTEKDIKTI atas dukungan dana dalam kegiatan Pengabdian Masyarakat program Prototipe Teknologi Ke Masyarakat 2017.

\section{DAFTAR PUSTAKA}

Ahuja, G.N., \& Patwardhan, A.W. 2008. CFD and experimental studies of solids hold-up distribution and circulation patterns in gassolid fluidized beds. Chem. Eng. J., 143(13):147-160.

Ariwibowo, D., Yohana, E., Yulianto, M. E., Paramitha, V., \& Arifan, F. 2012. Pemodelan Dan Simulasi Proses Pengeringan Chips Mocaf. Metana, 8(02):7-12

Ariwibowo, D. \& Yulianto, M.E. 2013. Simulasi Perpindahan Massa pada Batas Fasa AirUdara Untuk Pengering Chips MOCAF. Majalah Gema Tekologi. 22(1): 31-36.

Ariwibowo, D. \& Yulianto, M.E. 2014. Peningkatan Produktivitas Proses Pengeringan Chip MOCAF Dengan Alat Pengering Tray Resirkulasi. Prosiding Polines Engineering Seminar II 2014. ISBN 978-979-3514-46-8

Handayani, S.U., Yulianto, M.E., \& Paramita, V. 2015. Efficacy of Zeolite Adsorption on the Green Tea Production by Fluidized Bed Dryer. Research Journal of Applied Sciences, Engineering and Technology. 9(12):1128-1131.

Mujumdar, A.S. \& Kudra, T. 2002. Advanced Drying Technologies. Marcel Dekker. Inc. Basel. Switzerland.

Nwabane J.T. 2009. Drying Characteristics and Engineering Properties of Fermented Ground Cassava. African J. Biotechnol. 8 (5): 873-876 
Stubbing, T.J. 1999. Airless drying-development since IDS'94. Drying Technology. 17(7\&8): 1639-1651. DOI: 10.1080/07373939908917642

Yohana, E., Utomo, M.S.K.T.S., Ivantoro, T., Arifin, Z., \& Tauviqirrahman, M. 2016. Effect of
Temperature and Relative Humidity on the Performance of Steamer using Computational Fluid Dynamic (CFD). International Journal of Engineering and Technology. 8(4): 1737-1749. 